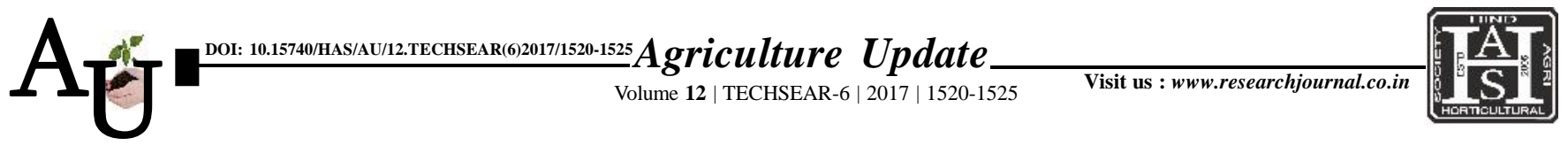

\title{
Research Article: Physical and cooking parameters of organic rice under non-chemical weed management
}

\author{
BAVAJI GUDI SHOBHA RATHOD AND E. SOMASUNDARAM
}

Article Chronicle : Received :

17.07.2017;

Accepted :

01.08 .2017

KEY WoRds:

Organic rice, Physical characters, Cooking

characters, Yield
SUMMARY : A field investigation was carried out at Tamil Nadu Agricultural University, Coimbatore to evaluate the effect of different non-chemical weed management practices on physical and cooking parameters of organic rice (CO (R) 50). The experiment was laid out in Randomized Block Design with three replication and ten treatments. The physical parameters like kernel length values varied from 5.86 to $6.10 \mathrm{~mm}$, kernel breadth varied from 2.03 to $2.11 \mathrm{~mm}$, L/B ratio varied from 2.77 to 2.94 and cooking parameters like kernel length after cooking (KLAC) values ranging from 9.60 to $10.80 \mathrm{~mm}$, kernel breadth after cooking (KBAC) ranging from 2.80 to $3.42 \mathrm{~mm}$, linear elongation ratio (LER) ranging from 1.64 to 1.78 , breadth wise elongation ratio (BER) ranging from 1.00 to 1.19 , water absorption ratio ranging from 3.05 to 3.81 and volume expansion ratio ranging from 2.50 to 3.40. From this experiment mulching with biodegradable polythene sheet recorded the highest grain yield $\left(5557 \mathrm{~kg} \mathrm{ha}^{-1}\right)$ and quality parameters like kernel length, kernel length after cooking, kernel breadth after cooking, water absorption ratio and volume expansion ratio. But among different non-chemical weed management practices benefit cost ratio was found to be highest in Hand weeding on 15 DAT followed by Azolla inoculation.

How to cite this article : Rathod, Bavaji Gudi Shobha and Somasundaram, E. (2017). Physical and cooking parameters of organic rice under non-chemical weed management. Agric. Update, 12(TECHSEAR-6) : 15201525; DOI: 10.15740/HAS/AU/12.TECHSEAR(6)2017/1520-1525.
Author for correspondence :

\section{BAVAJI GUDI}

\section{SHOBHA RATHOD}

Department of Agronomy, Agricultural College and Research Institute (T.N.A.U.), COIMBATORE (T.N.) INDIA

Email: rathodshoba@ gmail.com

See end of the article for authors' affiliations 